\title{
Capturing the Mature Traveler: Assessing Web First Impressions
}

\author{
Audra Lukaitis and Bill Davey \\ RMIT University, Melbourne, Australia
}

\section{Audra.Lukaitis@RMIT.edu.au; Bill.Davev@RMIT.edu.au}

\begin{abstract}
This paper proposes a method of assessing hotel web sites in a way that may allow prediction of first impressions of those web sites. A model is presented that combines the ideas of media frames as defined by Matthes and Kohring and work on first impressions by Kim and Fesenmaier. To obtain information regarding the utility of this model a small sample of older travelers' first impressions was gathered and a number of web pages analyzed for frame content. The trial run with this sample showed that it is possible to obtain both cohesive results from potential searchers and to classify frames consistently between researchers. In the small sample it was found that older people (50+) with travel aspirations did make quick judgments in terms of "first impression" and were favorably impressed by pages that "inspired" users and appeared easy to understand and navigate. There was considerable difference between first impressions of the same page, but subjects reported similar reactions to pages with the same frame elements.
\end{abstract}

Keywords: web page evaluation, models of e-commerce, media frames, first impressions

\section{Introduction}

IPK International (2008) has identified the take up of the internet as one of the four main drivers of global travel and tourism growth. Various empirically based reports confirm the growth and use made of the internet in touris $m$ and destination marketing by providers and travelers, and reinforce the importance of the internet as a marketing distribution channel. Studies confirm that more people are researching the internet for travel related information; more people are booking travel products using the internet. The European Travel Commission (2008) found that

- Over $70 \%$ of USA internet users nominated the web as their main source for travel research

- More than half of internet users in France book their travel online

- In the UK the internet is the preferred method to book holidays

Material published as part of this publication, either on-line or in print, is copy righted by the Informing Science Institute. Permission to make digital or paper copy of part or all of these works for personal or classroom use is granted without fee provided that the copies are not made or distributed for profit or commercial advantage AND that copies 1) bear this notice in full and 2) give the full citation on the first page. It is permissible to abstract these works so long as credit is given. To copy in all other cases or to republish or to post on a server or to redistribute to lists requires specific permission and payment of a fee. Contact Publisher@InformingScience.org to request redistribution permission.
In the Australian state of Victoria (Tourism Australia, 2008):

- In $2007,68 \%$ of international le isure visitors planned the ir trip on line to get internet information and $43 \%$ booked Online.

- $41 \%$ of international le isure visitors got their information from the internet, $29 \%$ from a friend or relative in Australia, 24\% from a Travel Agent, 20\% from 
a travel book and $17 \%$ from a past visit compared with $2 \%$ from the electronic media, print media or tour operator.

- Just over half, 53\% of interstate leisure vis itors get their information from the internet, $4 \%$ from airlines, $3 \%$ from motoring associations, a tourist office or travel agent respectively.

Nielsen ("Aussie internet usage...," 2008) estimates that of the top ten uses of the internet in Australia $44 \%$ of users will purchase air tickets and $37 \%$ will book accommodation.

The use of web sites has become a vital marketing distribution channel for the tour ism industry, that enables travelers or their intermediaries to research, book travel, make hotel reservations and hire a car amongst other things. The importance of destination websites has become a given.

Given the commercial importance of web sites we would expect significant research to be available indicating how a web site could be improved or identif ied as less than ideal. Park and Gretzel (2007) have conducted an extensive meta-analys is of the literature studying hotel web site characteristics and their effectiveness. They found that the most used factors among the published research community are:

- information quality,

- ease of use,

- security/privacy,

- responsiveness,

- customer service,

- interactivity,

- accessibility,

- navigation,

- visual appearance,

- personalization,

- trust,

- brand/reputation,

- incentive (in order)

Molich, Ede, Kaasgaard, and Karyukin (2004) found that professional usability organizations gave wildly different views of sites. In a study of nine organizations 232 out of 310 found were only reported by one organization. Only two problems were reported by more than six organizations.

This apparent difficulty in determining the value of a web site is further exacerbated by another fact. Lindgaard, Fernandes, Dudek, and Brown (2006), in a study investigating how quickly people form an opinion about web page visual appeal, found that the "visual appeal" of a website is judged within 50msecs (a 20th of a second). This seemingly instant response was found to match with the opinion of the same person after longer periods of study. Kim and Fesenmaier (2008) proposed that the more "inspiring" a web page is the more likely it is to result in a favorable first impression. They cite Thrash and Elliot (2003) who studied inspiration as a Psychological Construct, where inspiration is defined as an "infusion" of an idea, purpose, feeling or impulse. In the Kim and Fesenmaier (2008) study "inspiration" is a potential factor that contributes to a users' first impression formation. They go on to propose that there is a link between inspiration and usability with favorable first impressions and propose a "persuasion" framework. This is an important development in the literature as clearly a fundamental in any communication transaction is to "get attention" first. Therefore in terms of online destination distribution, initially there people must look further at a web site before they hopefully book a stay at a hotel or purchase an air- 
line ticket. The difference between detailed study of a whole site as opposed to the look of a first page is noted by O'Connor (2005). He notes that there are conflicting viewpoints on web design, characterized as the "aesthetic school" and "functionalists". One promotes the use of visual and multimedia elements, the other focuses on content over aesthetic appearance. In this study we were interested in the general question of how a web page designer might construct sites from the point of view of Initial Impression. We needed to find a way of linking what Is on a page to the Impression created by that page. We were also Interested In a model that would allow a quick meaqsurement of how pages are received by specific groups as the area of Interest (tourism sites) has usually been segmented Into groups, often by age.

\section{The Model}

\section{Part 1 - First Impressions}

Work by Kim and Fesenmaier (2008, p. 8)focuses attention on "first impressions" of web pages. They cite research indicating that initial impressions happen very quickly

"Studies indicate that individuals form an initial impression of an object within a short period of time: 3 seconds (Lindgaard et al. 2006); 4 seconds (Kaiser 2001); 5 seconds (Perfetti 2005); and 7 seconds (Ramsey 2004) in human-to human interaction. In addition, recent studies indicate that this time span may be very brief(i.e., as short as 50 milliseconds; Hotchkiss 2006) when applied to the online context."

Obviously if a first impression is negative it is less likely that a person will continue with that web site. This part of our model imagines the path of a web searcher to involve a go/no go step as soon as a first impression is formed. Figure 1, taken directly from Kim and Fesenmaier. It shows a stage called 'primacy' where a web searcher would commonly stop and continue with the next site. If this is the case the usability of the site is secondary to the searcher finding the site initially attractive.

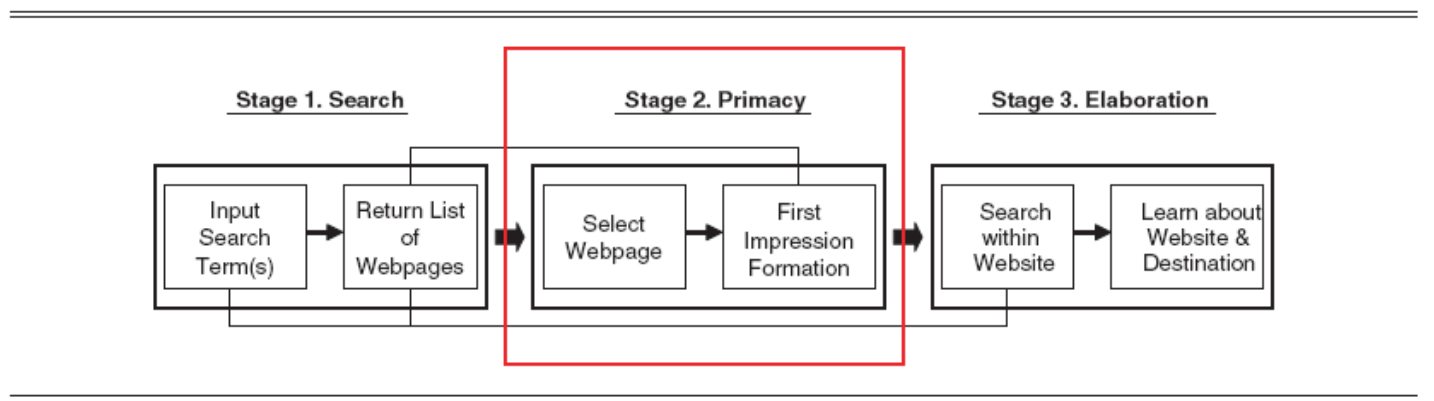

Figure 1. Information search process - reproduced from Kim and Fesenmaier, 2008, p. 4

This makes first impression a likely candidate as a metric of interest to web site developers and can throw some light on the "aesthetic" approach. Kim and Fesenmaier (2008) go on to identify a framework that they apply to web pages to look for a correlation between web site characteristics and first impression. Characteristics identified from a wide range of the literature were Hygiene factors of usability and informativeness and some potential factors, credibility, inspiration, involvement and reciprocity.

Table 1 - first Impression characteristics - created using the factors of Kim and Fesenmaier (2008), gives an indication of the meaning of each of these factors. 
Table 1: First Impression Characte ristics factors from (Kim and Fesenmaier 2008)

\begin{tabular}{|c|c|}
\hline Hygiene factors & \\
\hline Infor mati veness & Usability \\
\hline INFO1 provides a variety of information & USE1 is easy to understand \\
\hline INFO 2 provides useful information & USE2 is easy to use \\
\hline INFO3 provides up-to-date information & $\begin{array}{l}\text { USE3 helps me to easily find the information I } \\
\text { need }\end{array}$ \\
\hline \multicolumn{2}{|l|}{ Potential factors } \\
\hline Credibility & Inspiration \\
\hline CRED1 is trustworthy & $\begin{array}{l}\text { INSP1 represents the destination in an appealing } \\
\text { way }\end{array}$ \\
\hline $\begin{array}{l}\text { CRED2 represents a touris } m \text { information provider } \\
\text { I can trust }\end{array}$ & $\begin{array}{l}\text { INSP } 2 \text { helps me to be imaginative about the des- } \\
\text { tination }\end{array}$ \\
\hline $\begin{array}{l}\text { CRED3 represents a tourism office that will keep } \\
\text { its promises }\end{array}$ & INSP3 inspires me to visit the destination \\
\hline Invol vement & Reciprocity \\
\hline INV1 is highly interactive & RECP1 offers travel brochures I like to request \\
\hline $\begin{array}{l}\text { INV2 helps me become involved in planning my } \\
\text { trip }\end{array}$ & $\begin{array}{l}\text { RECP } 2 \text { enables me to directly contact the tour- } \\
\text { is } m \text { office }\end{array}$ \\
\hline \multirow[t]{2}{*}{ INV3 is enjoyable/fun to plan my trip } & RECP3 provides helpful customer service \\
\hline & $\begin{array}{l}\text { RECP4 enables me to reg is ter for special offers, } \\
\text { news letter, pers onalization, etc. }\end{array}$ \\
\hline
\end{tabular}

The potential factors were found by Kim and Fesenmaier (2008) to be not as important as the hygiene factors. They attribute this to the type of use that the web site owner seeks to make by their web sites. Our model would seek to determine the first impression of web pages from the viewpoint of all of these factors.

\section{Part 2 - Media Frames}

It seemed logical to us that this outcome (some web pages give better first impression than others) requires a further measure of the constitution of the web page. If we can conclude "web pages with this nature give better first impressions than those with that" for a given group of web searchers, then we can start to improve the pages. Lindgaard et al (2006, p. 125) attempted to answer questions of this type for the much simpler single issue of visual appeal and concluded:

"Our second ambition was to begin to understand what specific design attributes may contribute to visual appeal. That was too hard to do, at least using the method we employed here, and probably because the relationship between individual design features and the first holistic impression may not be as simple as we thought."

Since our ambition is to look at first impressions over a wide range of factors, we need a usable means of identifying screen attributes. An area of research that seemed to be useful was that used to analyze communication media. In this area researchers seek reliable conclusions about trends in reporting of events in the media. They do this by analyzing sources in terms of media frames. The definition of a media frame that we found most useful was that of Reese (2008, p. 150) 
"Frames are organizing principles that are socially shared and persistent over time, that work symbolically to meaningfully structure the social world"

If we are looking at things on a web page that influence a user in fractions of a second then the idea of socially shared organizing principles seems interesting. The research team quickly found the common existence of web elements that people recognized: navigation bars, advertising banners and forms are examples. Matthes and Kohring (2008, p. 259) saw a problem with previous research that had involved mostly subjective coding of frames:

"In other words, one runs the risk of extracting researcherframes, not media frames. This is because the perception and coding of frames strongly depend upon how the researcher perceives the issue."

To overcome this lack of objectivity they propose identifying elements, tested by interjudge reliability measure. Then taking these elements and submitting them to a cluster analysis to determine the frames. In our case a frame would then be a unique pattern of web page elements, and their distribution, that appears in several web pages with similar first impressions. This approach would appear to allow us to identify patterns of elements that have greater impact on first impression formation. Hence a designer would have detailed information about what is lacking in the web page.

We therefore propose a model that identif ies for a given customer population and a given web sector the relationship between media frames and first impression. (See Figure 2.) The actual correlation would be presumed to vary between different mixes of customer and site industry so that the correlation would need to be established at points in time for each combination. The correlation could then point out to developers what aspects of web page elements would be more likely to result in favourable first impression.

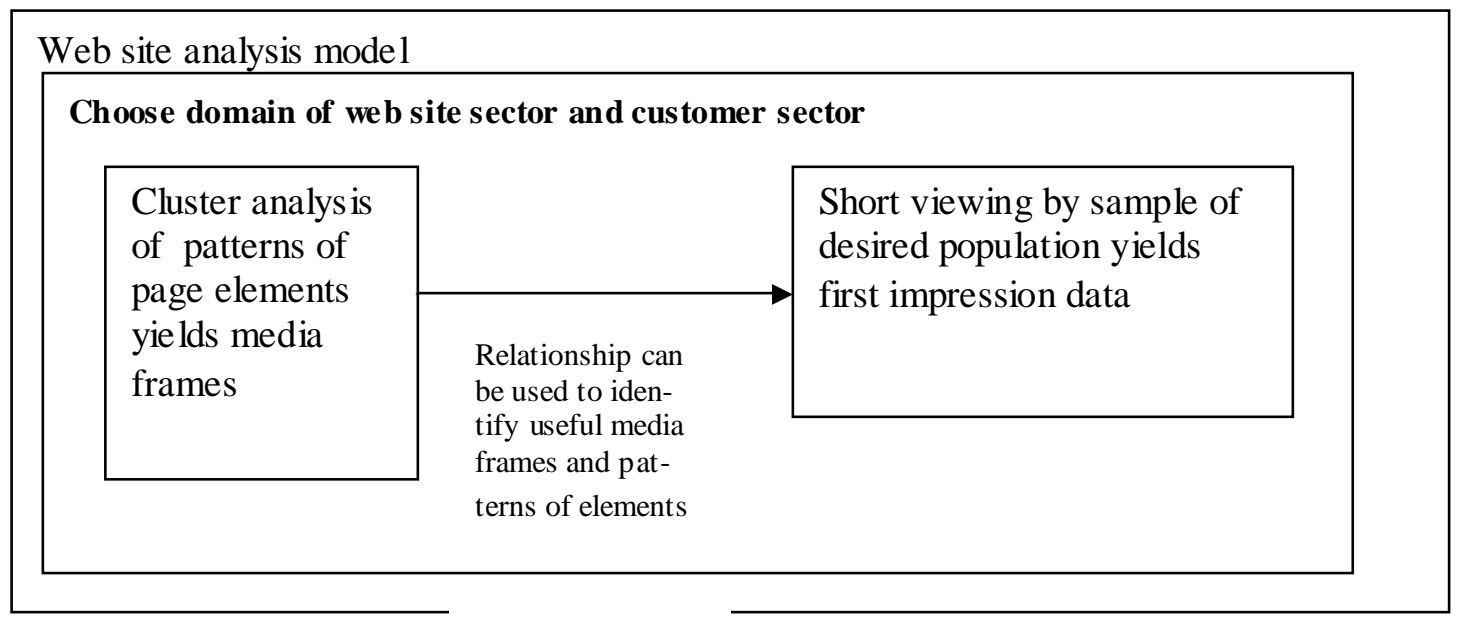

Figure 2: A model for analysing web sites

\section{Research design}

A short experiment of interest to us was chosen to allow a 'proof of concept' for this model. A simple requirement of any web site is that people coming to the front page should be encouraged to enter the site. Our chosen industry was hotels and we chose the market of Melbourne Australia, since we have considered this industry sector in prior research. This is a non-trivial tourism market with 1,076,600 international vis itors in 2006 (Melbourne City Council, 2007). A very small number (20) of front pages was captured on the same day so that we could have a variety of 
pages from a single industry, but so that showing them to people would not be inconveniently long.

\section{First Impression Experiment}

For our customers we chose older travelers. This was both to provide some contrast from other studies of younger people and as this sector is sometimes predicted as being a growing market. Our population was a convenience sample and included an unusual proportion of people with a long history of international travel. It was intended that the age group bias results, but the choice of mostly experienced travelers may also have had an effect. In our market this segment spent over two billion dollars during 2007 and represents a segment growing at 4\% annually (Tourism Australia, 2008)

A convenience sample of 20 Australian potential travelers was chosen ranging in age from 50 to 85 years of age. These were academics and administrators from the department of Business Information Technology at RMIT University. These people are members of a university that requires significant travel of all employees, and so are well traveled. A scenario was presented to each participant:

"Dear friend (50+), look at this picture and tell me, ifyou had won the lottery and were about to travel, if you would use this web site to book. You must do this for multiple sites and you only get 5 seconds to look at each. When I have shown it to you please give me an answer out of 5."

Each participant was shown a 20 web pages captured and stored as pictures (to provide comparability with Kim and Fesenmaier (2008). We selected a 5 second standard for showing web pages to participants, chosen as a compromise between other researchers ( 3 seconds - Lindgaard et al., 2006; 4 seconds - Kaiser, 2001; 5 seconds - Perfetti, 2005; and 7 seconds - Ramsey, 2004.) A simple program was written to present pages for 5 seconds each with a manual start to each picture. This allowed sufficient time for subjects to respond between each picture. Each web page was rated on a Likert scale from "strongly disagree" to "strongly agree" as an answer to the assertion "I would use this site to book travel." The purpose of this first test was to see if a fairly narrow population would have a range of reactions to the web sites chosen from a narrow commercial field. We were also interested in seeing if the same person reacted the same way to pages we later decided had the same frames. The outcome of this experiment could never be a conclusion about travelers as the sample is too small and poorly chosen. It could yield a 'non-result' in that we could find that there is no variation in reaction to all the web pages. This would tell us nothing about the model. If we found variation, and if the variation was in some way linked to the nature of the pages, then the model is worth trying in a sensible sized trial.

\section{Media Frames Experiment}

Each of the web pages was subjected to analysis of content frames using the method suggested by Matthes and Kohring (2008):

"every frame is characterized by a specific pattern of variables. Conceived this way, frames are neither identified beforehand nor directly coded with a single variable. Instead, the variables that signify single frame elements are grouped together by hierarchical cluster analysis."

The two researchers talked about what an element might be and decided that it would be better to check each page geometrically, deciding on elements as we went. Elements would be anything we saw as being a 'principle that is socially shared and persistent over time, that works symbolically to meaningfully structure' the page. That is an element that we think users would recognize as an element of the page in a short period of time. Thus each page was independently assessed as a number of coded elements. Each element was then coded in terms of the extent to which it filled the categories of Informativeness, Usability, Credibility, Inspiration, Involvement, and Re- 
ciprocity. Each page yielded a rich table of values of elements and their nature. Again the number of pages and researchers is too small to draw any conclusions about what frames might appear in web pages, but the possibility of low interjudge reliability would make the model look not useful.

\section{Results}

\section{First Impressions}

The number of 20 is a small sample intended to generate a first impression score to be compared with the second stage of the analysis. It was not intended to be statistically significant and no analys is was intended within the population. A quick analys is was conducted to see if the sample contained any anomalous results that might make the impression score particularly suspect.

Average score first impression ranged across the sites from 1.8 to 3.73. These differed from the mean of all scores at the $95 \%$ confidence level, indicating that the web sites were seen as being different from each other (eliciting a significant range of first impressions.) $47 \%$ of all responses were negative and $30 \%$ positive with the rest undecided.

Individuals sometimes showed little variation in their ratings (rated most sites as being the same). A second analysis was conducted that removed those responses with a range of 2 across the 20 sites. This new subset showed a variation of average rating from 1.67 to 3.92 .

Both of these results indicate that the average first impression response has some reliability as a measure of how old people (please note, younger than the research team!) might have as a first impression of a web site.

\section{Media Frames}

Two researchers decided on the nature and number of elements within each web page and independently assigned values to each from the attribute list. This was done for just the 20 web sites as an attempt to determine the practicality of the process. Interjudge reliability measures were then calculated for what frames were identified. This yielded a Cohen Kappa of 0.58, indicating that it is possible to identify frames. Scores were allocated for each of the elements in the frames. This yie lded a Cohen Kappa of 0.45. A cluster analysis was unable to identify media frames within the pages and these frames as the numbers were too small. The researchers were in agreement over three attributes of page elements on sufficient pages to be able to classify some pages as being higher or lower in two attributes: inspiration and usability (Using the definitions in Table 1 above). Even when the same physical element was identified by both researchers, elements such as Informativeness, Credibility, Involvement, and Reciprocity were rated very differently across the pages chosen. It seems that, as was found by Kim and Fesenmaier (2008), these are difficult decisions.

\section{Conclusion}

The model we have presented here builds on significant work in assessing tourism web sites and asks the question "what is a web page made of?" To answer that question we have looked at another area of enquiry that seeks to find meaning in a complex world- the area of media analysis. We see the techniques of usability analys is that as being slanted towards whole sites and having some problems with consistent outcomes. Instead we have looked at the pivotal moment of first impression of a web site. The analys is of pages using media frames was found to be more difficult than looking at web pages overall, but has the potential to lead to more detailed information of use to designers. First impressions were found to vary with web sites and sufficient homogeneity in the small sample suggests that first impression is a valuable metric for web site develop- 
ers. Although some consistency was found in rating pages using media frames, no frames emerged from the analys is. A larger study would be required to allow a sensible cluster analysis.

In the small sample it was found that older people (50+) with travel aspirations did make quick judgments in terms of "first impression" and were favorably impressed by pages that "inspired" users and appeared easy to understand and navigate. Older travelers were found to be impressed by slightly different factors than those influencing students used in other studies.

\section{References}

Aussie internet usage overtakes TV viewing for the first time. (2008). Nielsen Online. Retrieved June 24, 2008 fro $\mathrm{m}$ http://www.nielsen-online.co m/pr/pr 080318 AU.pdf

European Travel Commission. (2008). New media review from the European Travel Commission. Retrieved June 3, 2008 fro $\mathrm{m}$ http://www.etcnewmedia.com/review/default.asp

Kim, H., \& Fesenmaier, D. R. (2008). Persuasive design of destination web sites: An analysis of first impression. Journal of Travel Research, 47(3), 3-13.

Lindgaard, G., Fernandes, G., Dudek, C., \& Brown, J. (2006). Attention web designers: You have 50 milliseconds to make a good first impression!! Behaviour \& Information Technology, 25, 115-126.

Matthes, J., \& Kohring, M. (2008). The content analysis of med ia frames: Toward improving reliability and validity. Journal of Communication, 58, 258-279.

Melbourne City Council. (2007). Melbourne - A snapshot. Retrieved July 12, 2008 from http://www.melbourne.vic.gov.au/info.cfm?top=269\&pg=2326

Molich, R., Ede, M. E., Kaasgaard, K., \& Karyukin, B. (2004). Comparative usability evaluation. Behaviour and Information Technology, 23(1), 65-74.

O'Connor, P. (2005). Conflicting viewpoints on web design. In J. E. Mills \& R. Law (Eds.), Handbook of consumer behavior, tourism and the internet (pp. 225-230). Hawo rth Press.

Park, Y. A., \& Gretzel, U. (2007). Success factors for destination marketing web sites: A qualitative metaanalysis. Journal of Travel Research, 46(1), 46-63.

Reese, S. D. (2008). The framing project: A bridging model for med ia research revisited. Journal of Communication, 57(1), 148-154.

Riley, D., Battye, R., \& Marshall, J. (2004). Travel in Australia 2003: Annual results of the international and national visitor surveys. Tourism Research Australia, Survey Research Section. Retrieved June 21, 2008 from

http://www.tra.australia.co m/content/documents/IVS/travel\% 20in\%20australia\%20results\%20of\%20th e\%20international\% 20and\%20national\% 20v isitor\%20survey\%202003.pdf

Tourism Australia. (2008). Mature age visitors in Australia 2007. Retrieved May 2, 2008 from http://www.tra.australia.com/content/documents/Snapshots/2008/mature_07_FINAL.pdf

Travel Daily News Internation.com. (2008). Daily Travel \& Touris m News Portal for the International Travel Trade Market. Retrieved June 21, 2008 from http://www.traveldailynews.co m/pages/search?page=2\&query=IPK+International+internet 


\section{Biographies}

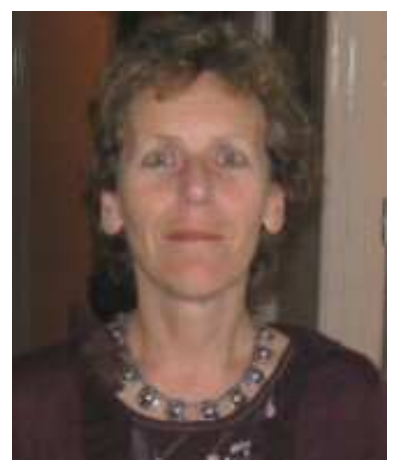

Audra Luakitis is a Senior Lecturer at RMIT University. She has teaching and research interests in effective commercial use of the internet.

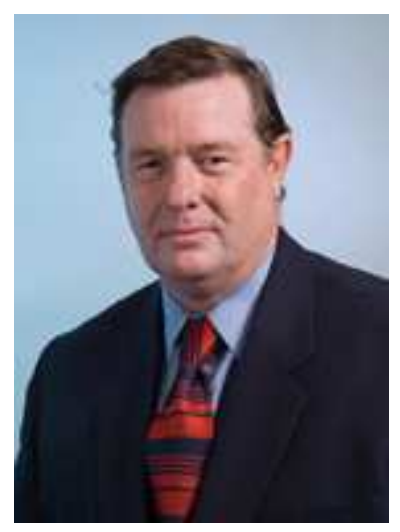

Bill Davey is a Senior Lecturer at RMIT University. His research interests are in qualitative research into effective integration of information systems in organizations. 